\title{
Ureteritis Cystica
}

National Cancer Institute

\section{Source}

National Cancer Institute. Ureteritis Cystica. NCI Thesaurus. Code C97143.

A non-neoplastic lesion of the ureter characterized by the presence of multiple submucosal small cysts in the ureteral wall. It is caused by inflammation due to urinary tract stones or infection. 